\title{
ORCHID CONSERVATION: THE NEXT TEN YEARS
}

\author{
Philip Seaton ${ }^{1}$, Jonathan P. Kendon ${ }^{2}$, Hugh W. Pritchard ${ }^{1}$, \\ Dwi Murti Puspitaningtyas ${ }^{3}$ \& Tim R. Marks ${ }^{1}$
}

\author{
${ }^{1}$ Seed Conservation Department, Royal Botanic Gardens, Kew, Wakehurst Place, Ardingly, \\ West Sussex, RH17 6TN, U.K. \\ ${ }^{2}$ Conservation Biotechnology, Royal Botanic Gardens, Kew, Richmond, Surrey, TW9 3AB, U.K. \\ ${ }^{3}$ Bogor Botanic Garden, J1. Ir. H. Juanda No. 13, Bogor - West Java, Indonesia
}

\begin{abstract}
In 1996 the IUCN/SSC Orchid Specialist Group published a Status Survey and Conservation Action Plan that included a number of recommendations designed to address the problem of a projected imminent and rapid decline of species. Orchids remain subject to a multiplicity of threats in their natural habitats and, in addition to the usual suspects of habitat loss and land conversion, climate change has exerted a measurable effect on some orchid populations. Collection of orchids for traditional medicine is having a significant effect both within China and surrounding countries. Some progress has been made in achieving the targets set for Red Listing of endangered species in some countries, but other countries are lagging behind. In addition to successful initiatives in preserving natural habitats, a number of projects around the world have demonstrated that it is possible both to bring endangered species into cultivation and successfully reintroduce them into the wild. Orchid Seed Stores for Sustainable Use, with its goal of storing seeds representing a minimum of 1000 orchid species in institutes in at least 30 countries over the next five years, provides an example of what can be achieved by a small, dedicated group determined to share their technical expertise and develop a deeper understanding of the underlying science. There is, however, also an urgent need to promote awareness in the wider community about the importance of all sorts of biodiversity (not only orchids) through educational programs and involve people from as wide a range of backgrounds as possible..
\end{abstract}

KEY WORDS: seed storage, habitat, reintroduction, germination, collection

Environmental degradation attributable to human activity has been happening for centuries throughout the world. Islands have been particularly prone to such depredations. Pickering (2010) wrote that "A modern visitor to Mauritius, drawn by its perfect beaches or the wonders of its marine life, can have little idea of the paradise into which Van Neck's men (who claimed the island for the Dutch in 1598) had stumbled. Mauritius was clothed in dense forest of ebony and bamboo and filled with bewildering wildlife. There were over twenty types of bird found nowhere else in the world, including, of course, the dodo." Today a paltry $1 \%$ remains of the original forest.

In China the extinction of wildlife and wild places began much earlier. Slow at first, the degradation gradually accelerated and "an environmental richness counterbalanced by perpetual dangers from wildlife" was replaced by "a sedenterized human dominance accompanied by a relative security from wild animals, but also ... an impoverished life of the senses (our emphasis)" (Elvin 2004). It is difficult to believe that in times past there were elephants as far north as Beijing and rhinoceroses were almost as widespread.

Although today we tend to associate deforestation with human activities in the tropics, it is worth remembering that in England in 1712 John Morton summed up the prevailing attitudes when he proclaimed: "In a country full of civilised inhabitants timber could not be suffered to grow. It must give way to fields and pastures that are of more immediate use and concern to life." When the Plymouth Brethren landed in North America they found "a hideous and desolate wilderness ... the whole country was full of woods and thickets;" and they set about civilizing it with chilling thoroughness. Within two centuries their descendents had obliterated seven-eighths of the continent's natural woodland (and species such as the passenger pigeon) with an arrogance rivaling those in modern Amazonia (Mabey 1999).

Accounts of the enormous collections and imports of orchids in Victorian times make disturbing reading. Rittershausen (1993) quoted two authors 
from the early days of the Orchid Review: "Few, if any, of the admirers of Orchids, "who sit at home at ease', have any idea of the extent of the wholesale destruction of these plants which occurs in the process of their collection, particularly in Venezuela, and in the collection of cattleyas. Valleys are denuded of their primeval growths, for the forest giants, and the highest branches of some of these, is the home for some species of Cattleya, particularly the evervarying forms of Cattleya gaskelliana. In order to secure the best plants these trees are felled, and from the harvest thus procured only the very finest plants are taken, the smaller ones and seedlings being left to perish with their natural support on the ground" (1897). Another author wrote, "Of Cattleya labiata Pernambuco exported about 15,000 plants of eight leaves and upward during the season ending with April, 1909" (1910).

The losses continue. Orchids today remain subject to a multiplicity of threats in their natural habitats and, in addition to the usual suspects of habitat loss, land conversion and illegal collecting, it seems probable that epiphytes will be exceptionally sensitive to climate change (Benzing 2004), which has already had a measurable effect on some orchid populations (Koopowitz \& Hawkins 2012). Collection of orchids for traditional medicine is having a significant effect both within China and surrounding countries (Pant \& Raskoti 2013). The U.K. has lost $97 \%$ of its flowerrich meadows and grasslands in the last 50 years (Walker et al. 2004). When describing habitats around Puerto Vallarta, Mexico, Warford (1989) reported that "A woman born in El Tuito, a small town some 27 miles (44 kilometers) south of Puerto Vallarta, tells of the time, scarcely 22 years ago, when Highway 200 was lined every mid-October with magenta clouds of Schomburgkia galeottiana plants in flower. Driving down the highway today, not a single specimen of that magnificent species can be seen."

As recently as the 1970s, nursery benches in the U.K. were full of wild-collected species such as Paphiopedilum fairrieanum (Lindl.) Stein, which is currently reduced to one population. Paphiopedilum vietnamense O.Gruss \& Perner was discovered in northern Vietnam in 1997. "All known populations in the wild have been depleted by illegal collection since its discovery" (Perner 2012).

\section{The fate of orchids}

So what has gone wrong? Why are we still allowing this continuing loss of biodiversity in general, and of orchids in particular, to happen? Given the evidence it can be difficult to understand why so few people even notice. Still fewer appear to care. At least part of the answer may lie in what has been called the 'Shifting Baseline Syndrome', a phrase first coined by Daniel Pauly (Arbesman 2012) to explain the collapse of fish stocks off the shores of Newfoundland and Cape Cod. This indicates that each new generation accepts the state of the planet they see around them as being the norm and uses that baseline to evaluate changes in the environment taking place in its lifetime. It is only when you read the accounts of past authors such as Darwin and Wallace that the full scale of what we have already lost becomes all too apparent.

All that remains of the dodo in Oxford's Natural History Museum are the head and the bones of a foot. One can only wonder if this is going to be the fate of many orchid species in the not-too-distant future. How many orchids are fated to be remembered only as dried pressed specimens in herbaria? Or are our orchids going to be like Brazil's beautiful blue Spix's macaw (Cyanopsitta spixii (Wagler)), which is now found only in captivity (Juniper \& Yamashita 1990; Juniper 2002).

Environmentalists around the globe were delighted when Barack Obama vowed in his inaugural address to his second term of office to put climate change center stage in his next term as U.S. President, saying "We will respond to the threat of climate change, knowing that the failure to do so would betray our children and future generations." On 23 August 2012, Robert Watson (past president of the Intergovernmental Panel on Climate Change - IPCC) appeared on television to suggest that we are extremely unlikely to meet the target of limiting global average temperatures to a $2^{\circ} \mathrm{C}$ increase; more likely it will be higher. On 16 September 2012, Arctic ice shrank to its lowest seasonal minimum since records began in 1979 (Pearce et al. 2012). We know that climate change is also affecting orchid populations. In his landmark 32-year study of a population of Ophrys sphegodes Mill., Hutchings (2010) found that, given some variation, peak flowering advanced by about half a day per year during the study period. In addition, fertilization rates of $O$. sphegodes are low in the U.K. and, although $O$. sphegodes is facultatively autogamous, 
it also is cross-pollinated by a rare solitary bee. Unless the phenologies of $O$. sphegodes and the bee respond similarly to climate change, there is a risk that rates of pollination will be reduced in the future .

\section{Habitat conservation}

Ideally the problem of conservation would be solved by preserving habitats such as El Pahuma in Ecuador (Seaton 2005) and La Planada Nature Reserve in Colombia (Orejuela Gärtner 2011), bearing in mind that habitats themselves may be subject to future change. It is unlikely, however, that it is going to be possible to conserve all habitats, and we should perhaps begin to examine our priorities and begin to identify Important Orchid Areas (IOAs) in a similar way to areas that have been identified as being Important Plant Areas (IPAs) (Anderson 2002; Foster et al. 2012).

Orchids are, of course, just one component of a complex physical and biological web of relationships that constitute a particular ecosystem. A species may be adapted for example to a particular temperature range and relative humidity. In order to germinate in their natural environment, seeds need to encounter a particular mycorrhizal fungus and may be reliant upon a different fungus at a subsequent life stage. They often need a specific pollinator, which in turn will be reliant on a particular set of plants to complete their life cycle. The relationships of orchid flowers with their insect pollinators is often intricate. As temperature and precipitation change, we do not know whether there will be synchrony of phenologies between orchids and their pollinators (Hutchings 2010) or what the potential consequences may be for their mutual survival. The majority of tropical orchids are epiphytes, growing in tree canopies. Recent findings on the adverse effects of climate change on populations of large and old trees indicate that loss of such trees could have a disastrous effect on certain epiphytic species (Laurance 2012). Whigham (pers. comm.) suggested that orchids are particularly sensitive to environmental change and could be used as indicators of change and act as bioindicators/canaries in the coalmine.

\section{Reintroductions}

There are, nevertheless, reasons to be optimistic. More people are participating in orchid reintroductions around the world, including a number of the partners of Orchid Seed Stores for Sustainable Use (OSSSU). There are, for example, reintroduction programs for Cattleya quadricolor B.S.Williams in Colombia (Seaton \& Orejuela Gärtner 2009), Cyrtopodium punctatum (L.) Lindl. in the Fakahatchee Strand in Florida, U.S.A. (Ferreira et al. 2012), Cymbidium finlaysonianum Lindl. and Grammatophyllum speciosum Blume in Singapore (Yam et al. 2010) and Cypripedium macranthos Sw. in China (Seaton 2010). The Royal Botanic Gardens, Kew, is participating in reintroduction projects for the critically endangered endemics Epidendrum montserratense $\mathrm{Nir}$ in Montserrat and Angraecum longicalcar (Bosser) Senghas in Madagascar. Montserrat's Soufrière Hills volcano, dormant for centuries, erupted in 1995 and is still active today. The eruption triggered pyroclastic flows, destroying large areas of forest. One area in the western part of the island where $E$. montserratense is commonly found still suffers from ash clouds, venting from the active volcano. Not only does the hot ash damage the host trees, but it also blocks rivers, causing flash floods, which destroy river valley vegetation. Another area of suitable habitat, in the Silver Hills in northern Montserrat, has largely escaped volcanic damage but has become even more important for agriculture and building land for the island's remaining human population. Two collections of seeds from E. montserratense are now safely stored in Kew's Millennium Seed Bank. Living plants, rescued from dead mango (Mangifera indica L.) trees, have been taken to the Montserrat National Trust's newly developed botanic garden where they are being cultivated for future display, and seedlings have been cultivated in Kew's Conservation Biotechnology section (CB).

The problem in Madagascar is of a different nature. Recent expeditions to investigate the status of A. longicalcar in its natural habitat found that just nine clumps remained: six on a ridge beyond a village in central Madagascar's Hauts-Plateaux (three producing fruiting spikes) and three between the village and a road. Those nearest the road were in a poor state, and one clump had suffered illegal collection; about ten large shoots had been cut off the rocks, leaving three small shoots. Another of the three clumps had been reduced in size considerably and was at risk eventually 
of falling off the cliff top on which it was growing. Several plants that have been raised from seedlings at Parc Botanique et Zoologique de Tsimbazaza (PBZT) and transferred to a shade house in the village were subsequently planted out two years ago on a ridge of similar habitat to the ones on the ridge. These have established well, with many large, deep green leaves. The project is in the early stages and will run for several years. It is both an extension of previous work on methods for collecting highly germinable immature seed and part of a new collaborative project involving the use of ecological and mycorrhizal information to facilitate the reintroduction of threatened species. Seed baits and the collection of mature roots are being employed to identify and culture mycorrhizal fungi. Material (seed, seed pods, and roots) has been cultured, and seedlings are being raised in CB at Kew (http:// www.kew.org/about-kew/press-media/press-releases$\mathrm{kew} / \mathrm{madagascar-orchid-conservation-illinois-}$ college). The involvement of the local community is key in maintaining and protecting the sites in the long term. After growing on in the shade house, the village children are reintroducing plants previously raised at PBZT. They each have individual plants that they care for and have been given project $t$-shirts. This local involvement has helped with engagement and is an important part of the species' management, which now includes husbandry of reintroduced plants and creation and maintenance of fire breaks around the sites.

\section{Orchid Seed Stores for Sustainable Use (OSSSU)}

OSSSU, with its goal of storing seeds representing a minimum of 1000 orchid species in institutes in at least 30 countries by 2016, demonstrates what can be achieved by a small, dedicated group determined to create a global network of orchid seed banks, exchange technical expertise, and develop a deeper understanding of the underlying science. Initially focusing on biodiversity hotspots in Latin America and Southeast Asia, this Darwin Initiative (Defra, U.K.) project commenced in 2007, with regional workshops held in Chengdu, China, in October and Quito, Ecuador, in November of the same year. The network soon expanded to encompass other tropical regions and also countries with temperate climates. A four-day workshop for participating countries was held at Jardín Botánico Lankester, Costa Rica, in September
2010 to summarize the work carried out thus far and plan the next stage.

Good communication is key in setting up and maintaining such a broadly based coalition, and additional meetings take place whenever and wherever the opportunity arises. Thus colleagues from botanic gardens, research institutes, and universities from around China were able to meet at the National Orchid Conservation Center in Shenzhen in April 2012 to discuss the development of an in-country program that would support the conservation of their 1350 orchid species. Likewise, representatives from 11 participating countries held a workshop at the $8^{\text {th }}$ International Orchid Workshop held at Orquideario Soroa, Cuba, in October 2011. From the original 15 countries in Latin America and Asia (plus the U.K.) the network has continued to expand, with 37 institutions in 25 countries participating to date.

Although a number of institutes in participating countries have the resources to collect material from the wild, for practical reasons OSSSU is primarily focused on living collections, and these play a key role in ex situ conservation efforts. However, it is vital that seed is collected from as broad a genetic base as possible, and selfing of plants is only used as a last resort when there is only one rare plant available, for example. Where possible, it would be desirable to establish collections containing significant numbers of plants of particular targeted species to reflect the genetic diversity within those chosen species.

It is important to recognize that conservation is not just a problem for scientists and, if we are to succeed in our mission to save orchids for future generations, we need to involve groups beyond the scientific community and promote a wider interest in conservation through Citizen Science projects. To this end OSSSU has obtained funding to host two workshops for holders of the National Collections of Orchids in the U.K. with the aim of encouraging them to pollinate their unique plants and collect seed for storage and research at Kew's Millennium Seed Bank. The National Plant Collection ${ }^{\circledR}$ scheme is hosted by Plant Heritage, the U.K.'s premier plant conservation charity. Individuals or organizations undertake to document, develop, and preserve a comprehensive collection of one group of plants in trust for the future. For example, the National Collection of Maxillaria 
currently holds approximately 275 different species. The collection is underpinned by an impressive series of volumes of drawings and notes on each species. Each plant is photographed when in flower, and there is a comprehensive slide collection that is currently being digitized. A few plants are also represented as paintings. Kew has provided the herbarium sheets for pressed specimens, and there is a corresponding spirit collection of flowers. All of these are destined for Kew's Herbarium as an important resource for future investigators (Seaton 2011). Collections have the potential to act as important educational tools, increasing awareness of the enormous diversity of the orchid family among orchid growers and the general public.

A major opportunity to conserve orchids is evident in the storage of their seed. Many species produce enormous numbers of tiny seeds allowing the conservation of large numbers in comparatively small volumes. This can both ensure the retention of genetic diversity and potentially facilitate the longterm survival of these seeds under suitable conditions. Orchid seeds are considered to display an orthodox behaviour and extended longevity when subjected to drying $\left(<5 \%\right.$ moisture content) and freezing $\left(-20^{\circ}\right.$ C) under the conditions commonly utilized in many seed banks. Evidence from the initial phase of the OSSSU, where participating laboratories used the same conditions to dry, store, and germinate seeds, showed that maintaining a high level of viability could vary among species stored under these conditions. A range of Coelogyne species lost their viability, whereas Dendrobium species showed a mixed response when germinated on Knudson C (Knudson 1946) medium after 12 months of storage at $-20^{\circ} \mathrm{C}$ (Table 1). Species of Vandopsis, Phalaenopsis, Cymbidium, and Arundina all retained maximum viability over some 18 months.
The suitability of this storage regime is part of ongoing research in a range of species to determine the effects of temperature and seed moisture content, both of which are recognized as major factors that affect the duration over which seeds can be successfully conserved. For example, in the temperate terrestrial Gavilea littoralis (Phil.) M.N.Correa, in which moisture content was reduced to c. $3 \% \mathrm{w} / \mathrm{w}$ through equilibration at $15 \%$ relative humidity, longevity was significantly promoted by storage in liquid nitrogen compared to that at $5^{\circ} \mathrm{C}$ (Table 2). However, such a temperature response can be modified by moisture content, as seen in the epiphytic species Guarianthe aurantiaca (Bateman ex Lindl.) Dressler \& W.E.Higgins (Seaton \& Hailes 1989), and in a range of Australian terrestrials (Hay et al. 2010). Specific sets of conditions can be identified that enhance the longevity of particular species, although the application of a more universal recommendation as a possible alternative to seedbanking conditions and applicability to a broader range of species await resolution. By working with a broad range of species, OSSSU partners are producing data that will increase our understanding of the basis of sustained longevity when orchid seed is stored at $-20^{\circ}$ $\mathrm{C}$ and, where possible, other temperatures.

Expression of seed viability can be measured in several ways. Partners of OSSSU have developed in vitro conditions for the successful asymbiotic germination of c. 240 species on a common medium (Knudson C). This is the first time that a large-scale comparison has been made using common procedures across a broad range of orchid species. Using a vital stain such as triphenyl tetrazolium chloride (TZ) establishes a base-line potential for germination and is critical in the recognition of sub-optimal medium. However, the technique can yield variable results with different types of seeds, and to improve the

TABLE 1. Viability and germination of temperate terrestrial Gavilea littoralis (Phil.) M.N.Correa seeds following one year of storage at different temperatures after equilibration of seeds at $15 \%$ relative humidity.

\begin{tabular}{|c|c|c|c|c|c|}
\hline & \multicolumn{5}{|c|}{ Seed storage temperature $\left({ }^{\circ} \mathrm{C}\right)$} \\
\hline & -196 & -70 & -20 & 5 & 20 \\
\hline Tetrazolium viability (\%) & $68.3 \pm 2.6$ & & & & \\
\hline Pre-storage germination & $41.1 \pm 4.5$ & & & & \\
\hline $\begin{array}{l}\text { Germination on } 1 / 2 \mathrm{~B} 5 \text { and } \\
\text { activated charcoal }\end{array}$ & $46.9 \pm 5.1$ & $35.4 \pm 2.3$ & $35.2 \pm 5.8$ & $29.5 \pm 4.6$ & $14.9 \pm 1.4$ \\
\hline
\end{tabular}


TABLE 2. Changes in the germination of Coelogyne, Dendrobium, and Xylobium species on Knudson C medium after 9 or 12 months of storage at $-20^{\circ} \mathrm{C}$.

\begin{tabular}{l|r|r|r}
\hline & \multicolumn{3}{|c}{ Storage duration (months) } \\
\hline Species & Initial & 9 & 12 \\
\hline Coelogyne asperata Lindl. & & & \\
\hline Coelogyne foerstermannii Rchb.f. & $35.4 \pm 1.7$ & & $1.9 \pm 0.5$ \\
\hline Coelogyne pandurata Lindl. & $81.5 \pm 3.4$ & $5.4 \pm 1.4$ & \\
\hline Coelogyne rumphii Lindl. & $99.5 \pm 0.3$ & & $6.8 \pm 2.0$ \\
\hline Dendrobium macrophyllum A.Rich. & $64.7 \pm 3.6$ & $1.1 \pm 0.5$ & \\
\hline Dendrobium mirbelianum Gaudich. & $69.6 \pm 3.7$ & & $52.8 \pm 0.6$ \\
\hline Dendrobium stratiotes Rchb.f. & $94.5 \pm 0.3^{\mathrm{a}}$ & & $0.6 \pm 0.3$ \\
\hline Xylobium undulatum (Ruiz \& Pav.) Rolfe & $95.6 \pm 0.6$ & & $81.3 \pm 1.7$ \\
\hline
\end{tabular}

${ }^{\mathrm{a}}$ Germination following one month of storage at $-20^{\circ} \mathrm{C}$

TABLE 3. Seed yield and size characteristics of two terrestrial species bearing small capsules.

\begin{tabular}{l|l|l|l|l}
\hline & $\begin{array}{l}\text { Capsule } \\
\text { DWT }(\mathrm{mg})\end{array}$ & $\begin{array}{l}\text { Total seeds } \\
\text { DWT }(\mathrm{mg})\end{array}$ & Mean seed DWT $(\mu \mathrm{g})$ & Total seeds/capsule \\
\hline Stenoglottis fimbriata Lindl. & $4.8 \pm 0.4$ & $1.9 \pm 0.2$ & $0.7 \pm 0.1$ & $2721 \pm 507$ \\
\hline Ponerorchis graminifolia Rchb.f. & $5.3 \pm 0.9$ & $2.2 \pm 0.6$ & $1.2 \pm 0.4$ & $1722 \pm 134$ \\
\hline
\end{tabular}

development of the red colouring associated with this stain a sucrose pre-conditioning stage has been used, initially with Cattleya species (Hosomi et al. 2011). The effect of storage on seed vitality can also be seen in more subtle responses; the rate of germination was both lowered and increased across a range of Cattleya species following three months of storage at $-20^{\circ} \mathrm{C}$ (Hosomi et al. 2012).

Sharing expertise has enabled partners to conserve enormous quantities of germplasm, potentially making material available for re-introduction programs. Seed production can be vast. The enormous $G$. speciosum capsules, weighing over $4 \mathrm{~g}$ (fresh weight), can contain as many as two million seeds, but even the smaller capsules of Aerides odorata Lour. can contain over 200,000 seeds. This level of fecundity can vary and is dependent upon seed and capsule size, whereas the much smaller capsules of terrestrial species Stenoglottis fimbriata Lindl. and Ponerorchis graminifolia Rchb.f. produce many fewer seeds (Table 3). Bearing in mind that seed weights of 0.3- $24.0 \mu \mathrm{g}$ have been identified across the family (Arditti \& Ghani 2000), this may indicate that seed yields are equally variable. The phenology of seed set and capsule maturation times have also been recorded to provide data for identifying suitable harvest times. Importantly, the point of mass seed maturity achieved at the end of capsule maturation is associated with a reduction in moisture content, which has been shown to be critical to successful storage in Phalaenopsis amabilis Lindl. hybrids (Schwallier et al. 2011). Taken from data for Brazil, Indonesia, Thailand, and Singapore, these times have varied from $>50$ to $>500$ days and could provide base data for potential differences related to climate change.

\section{The next ten years}

Although the problems faced by the natural world remain as serious as ever, we believe that it is a mistake to focus on these problems and not talk about the good things that are taking place. Quite simply the general public are turned off by all the doom and gloom. We need to share more positive stories to encourage people to engage with the problems. And people love orchids. Perhaps this is nowhere more evident than in Colombia, where the Ministry of Environment designated 2010 
as the National Year of Orchids, mentioning in the resolution that during the last 100 years Cattleya trianae Linden \& Rchb.f., Colombia's national flower, had lost $80 \%$ of its natural habitat. Happily, as with $A$. longicalcar, C. trianae is still cultivated by the local people in Colombia who assiduously protect their plants. On the other side of the Atlantic in South Africa, the Darling Wildflower Show has been held annually since 1917 and attracts thousands of visitors each year.

In 1996 the IUCN/SSC Orchid Specialist Group (OSG) published a Status Survey and Conservation Action Plan (Hagsater \& Dumont 1996) that included a number of recommendations designed to address the problem of the projected imminent and rapid decline of species. Progress towards achieving some of these goals has perhaps been sporadic but nevertheless encouraging. In addition to OSSSU there are many groups active around the world. The OSG (http:// iucn.org.orchid) itself continues to hold meetings in association with conferences at which members are attending, most recently in the U.K., Ecuador, the Czech Republic, Australia, and Singapore. The wide geographical spread of these meetings has allowed different groups of members to attend at least one meeting. Some progress has been made in achieving the targets set for Red Listing of endangered species in some countries, but other countries are lagging behind.

Deciding which species to preserve remains an ad hoc affair. According to the 'Noah Principle', all species are fundamentally equal, and everything should be saved regardless of its importance to humans; but perhaps we need to be more realistic and target particular species and habitats. We might also consider preserving the germplasm of some of the rarer varieties. They should be cloned before they die and are lost forever. Although orchids often are able to live for decades if not more than a century, some are short-lived in cultivation. A continuous production of high-quality specimens can be maintained using in vitro techniques with material conserved in a network of seed banks (Seaton 2007; Seaton \& Pritchard 2008).

One current focus for developing OSSSU is in the biodiversity hotspots of southern China where, in addition to their susceptibility to climate change, many species of Cypripedium and Paphiopedilum (horticultural value) and Dendrobium and Cymbidium (horticultural and medicinal value) are under threat from over-collection and habitat degradation from changes in land usage. Changes to vegetational zoning up mountain sides can also have dramatic effects upon the distribution of some species. Under rapidly changing pressures to adapt, certain species will inevitably die and may become extinct in the wild. By conserving the Chinese species as seed or as living collections and improving our understanding of the seed biology of this iconic family of plants worldwide, we have a greater opportunity to conserve many of these charismatic plants for future generations to use in horticulture and traditional medicine (Seaton et al. 2010).

There is no doubt that OSSSU has enabled more students to become engaged in orchid research activities, and it is no exaggeration to say that such projects can change people's lives. There is a need to find funding for more young people to attend and participate in conferences. We need to be engaging with a much wider audience outside the orchid community, explaining the importance of all sorts of biodiversity (not only orchids) through educational programs, involving people from as wide a range of backgrounds as possible, and sharing knowledge and delivering courses. The list of the 100 most threatened species as suggested by IUCN Species Specialist Groups (Baillie \& Butcher 2012) named the orchids Dendrophylax fawcettii Rolfe and Rhizanthella gardneri R.S.Rogers as representatives of Orchidaceae.

We need to approach the task with imagination. The Orchid Conservation Alliance (OCA) continues to raise funds to buy land for conservation in South America. Monies raised by Orchid Conservation International (OCI) have been used to fund conservation projects and also enabled production of stunning posters by students on the Natural History Illustration degree course at Blackpool and the Fylde College in the U.K. The first poster, illustrated by Ian Cartwright, told the story of Coryanthes kaiseriana G.Gerlach and its pollination by euglossine bees. The second poster, by Ruth Grant, showed Paphiopedilum rothschildianum (Rchb.f.) Stein in its natural habitat in Borneo. Above all we need to develop inspirational educational programs (Light et al. 2003) that teach schoolchildren about the wonders of the natural world and the opportunities for exciting careers whether based in a laboratory environment or studying orchids in the field. 
There is no shortage of research topics: pollination, inbreeding depression, and self-incompatibility, for example. Although not necessary in a horticultural context, the survival of reintroduced terrestrial orchids may be more successful if symbiotically raised material is used (Ramsay \& Dixon 2003). There is an urgent need for more field studies, particularly in the tropics, to establish the baseline data for orchid populations that will allow us to monitor future changes. The orchid world would certainly benefit from better coordination of dissemination of information about who is doing what and where.

\section{LiTERATURE CITED}

Anderson, S. 2002. Identifying important plant areas. Plantlife International, London, U.K.

Arbesman, S. 2012. Truth decay: the half-life of facts. New Scientist 215(2884): 37-39.

Arditti, J. \& A.K.A. Ghani. 2000. Tansley review No. 110 - Numerical and physical properties of orchid seeds and their biological implications. New Phytologist 145: 367-421.

Baillie, J.E.M. \& E.R. Butcher. 2012. Priceless or worthless? The world's most threatened species. Zoological Society of London, U.K.

Benzing, D.H. 2004. Vascular epiphytes. Pp. 175-211 in: Forest canopies (ed. M.D. Lowman \& H. Bruce Rinker). Elsevier Academic Press, Amsterdam.

Elvin, M. 2004. The retreat of the elephants: an environmental history of China. Yale University Press, New Haven, Connecticut.

Ferreira, D., M. Richards \& P.T. Seaton. 2012. Saving Florida's cigar orchid. Orchid Rev. 120: 158-161.

Foster, M.N., T.M. Brooks, A. Cuttelod, N. De Silva, L.D.C. Fishpool, A.E. Radford \& S. Woodley. 2012. The identification of sites of biodiversity conservation significance: progress with the application of a global standard. J. Threatened Taxa 4: 2733-2744.

Hagsater, E. \& V. Dumont (eds). 1996. Orchids-status survey and conservation action plan. IUCN, Gland.

Hay, F.R., D.J. Merritt, J.A. Soanes \& K.W. Dixon. 2010. Comparative longevity of Australian orchid (Orchidaceae) seeds under experimental and low temperature storage conditions. Bot. J. Linn. Soc. 164: 26-41.

Hosomi, S.T., R.B. Santos, C.C. Custodio, P.T. Seaton, T.R. Marks \& N.B. Machado-Neto. 2011. Preconditioning Cattleya seeds to improve the efficacy of the tetrazolium test for viability. Seed Sci. Technol. 39: 178-189.

Hosomi, S.T., C.C. Custodio, P.T. Seaton, T.R. Marks \& N.B. Machado-Neto. 2012. Improved assessment of viability and germination of Cattleya (Orchidaceae) seeds following storage. In Vitro Cell. Devel. Biol. Pl. 48: 127-136.

Hutchings, M.J. 2010. The population biology of the early spider orchid Ophrys sphegodes Mill. III. Demography over three decades. J. Ecol. 98: 867-878.

Juniper. T. 2002. Spix's macaw. Fourth Estate, London.

Juniper, T. \& C. Yamashita. 1990. The conservation of Spix's macaw. Oryx 24: 224-228.

Knudson, L. 1946. A new nutrient solution for the germination of orchid seed. Amer. Orch. Soc. Bull. 14:214-217.

Koopowitz, H. \& B.A. Hawkins. 2012. Global climate change is confounding species conservation strategies. Integrative Zool. 7: 158-164.

Laurance, W. 2012. Big trees: how the mighty are fallin'. New Scientist 213(2849): 39-41.

Light, M.H.S., S.P. Kell \& P.S. Wyse Jackson. 2003. The role of education and training in orchid conservation; an overview and critique. Pp. 357-382 in: Orchid conservation (ed. K. W. Dixon, S. P. Kell, R. L. Barrett \& P. J. Cribb). Natural History Publications, Kota Kinabalu, Sabah.

Mabey, R. 1999. The roots of civilisation (1988). Chatto and Windus, London.

Orejuela Gärtner, J.E., 2011. Orchids in the Mist. El Color de Colombia. Ediciones Artísticas.

Pant, B. \& B.B. Raskoti. 2013. Medicinal orchids of Nepal. Himalayan Map House Pvt. Ltd.

Pearce, F., S. Reardon \& C. Brahic. 2012. Laying claim to the wild, wild north. New Scientist 216(2885): 8 -10.

Perner, H. 2012. Paphiopedilum in China IV. Subgenus Parvisepalum, section Parvisepalum. Orchids 81:546555.

Pickering, J. 2010. The Oxford Dodo. The sad story of the ungainly bird that became an Oxford icon. Pub. Oxford University of Natural History.

Ramsay, M. \& K. W. Dixon. Propagation science, recovery and translocation of terrestrial orchids. Pp. 259-288 in: Orchid conservation (ed. K. W. Dixon, S. P. Kell, R. L. Barrett \& P. J. Cribb). Natural History Publications, Kota Kinabalu, Sabah.

Rittershausen, W. (ed.) 1993. 100 Years of orchids. Bardfield Books, U.K.

Schwallier R., V. Bhoopalan \& S. Blackman. 2011. The influence of seed maturation on desiccation tolerance in Phalaenopsis amabilis hybrids. Sci. Hort. 128: 136-140.

Seaton, P.T. 2005. On top of the world at the El Pahuma Orchid Reserve in Ecuador. Orchids 10: 748-757.

Seaton, P.T. 2007. Orchid conservation: where do we go from here? Lankesteriana 7: 13-16.

Seaton, P.T. and H.W. Pritchard. 2008. Life in the freezer. Orchids 76: 762-773. 
Seaton, P.T. 2010. Conserving Cypripedium macranthos. Orchid Rev. 118: 42-45.

Seaton, P.T. 2011. Ten years of Maxillaria magic. Plant Heritage NCH News, Autumn 2011, pp. 2-5.

Seaton, P.T. \& N.S.J. Hailes. 1989. Effect of temperature and moisture content on the viability of Cattleya aurantiaca seed. Pp. 17-29 in: Modern methods in orchid conservation: the role of physiology, ecology and management (ed. H.W. Pritchard). Cambridge University Press.

Seaton, P.T., H. Hu, H. Perner \& H.W. Pritchard. 2010. Ex situ conservation of orchids in a warming world. Bot. Rev. 76: 193-203.
Seaton, P.T. \& J.E. Orejuela Gartner. 2009. Saving Cattleya quadricolor. Orchids 78: 548-551.

Walker, K.J., P.A. Stevens, D.P. Stevens, J.O. Mountford, S.J. Manchester \& R.F. Pywell. 2004. The restoration and re-creation of species-rich lowland grassland on land formerly managed for intensive agriculture in the UK. Biol. Conserv. 119: 1-18.

Warford, N. 1989. Orchid species and habitats Around Puerto Vallarta, Mexico. Amer. Orch. Soc. Bull. 58: 26-35.

Yam, T. W., J. Chua, F. Tay \& P. Ang. 2010. Conservation of native orchids through seedling culture and reintroduction - a Singapore experience. Bot. Rev. 76: 263-274. 